\title{
THE ROUTINE USE OF FRESH FROZEN PLASMA IN OPERATIONS WITH CARDIOPULMONARY BYPASS IS NOT JUSTIFIED
}

\author{
E. C. J. Consten, MD \\ Ch. P. Henny, MD, PhD ${ }^{b}$ \\ L. Eijsman, $\mathrm{MD}, \mathrm{PhD}^{\mathrm{c}}$ \\ D. A. Dongelmans, $\mathrm{MD}^{\mathrm{b}}$ \\ M. H. J. van Oers, MD, $\mathrm{PhD}^{\mathrm{d}}$
}

\begin{abstract}
Background: The negative influence of cardiopulmonary bypass on hemostasis has been documented. Although abnormalities in platelet function are reported as the major cause of postoperative blood loss related to this hemostasis defect, fresh frozen plasma is often used in operations with cardiopulmonary bypass because it is thought to contribute to the reduction of postoperative bleeding complications. This study was designed to evaluate the effect of the administration of fresh frozen plasma after cardiopulmonary bypass on blood loss, transfusion requirements, and a number of coagulation parameters. Methods: In a prospective, randomized, doubleblind clinical trial 50 patients (mean age 63 years; 35 men/15 women) undergoing elective operation with cardiopulmonary bypass were randomly assigned to one of two groups: group $I(n=24)$ received 3 units of fresh frozen plasma after operation and group II $(n=26)$ received an equal amount of Gelofusine plasma substitute. At seven points before, during, and after operation hemoglobin concentration, hematocrit level, thrombocyte count, and coagulation parameters were analyzed. Study endpoints were the volume of blood loss and the transfusion requirement. Results: There were no significant differences between the two study groups in blood loss, transfusion requirement, coagulation parameters, or thrombocyte counts. Conclusion: The routine use of fresh frozen plasma in operations with cardiopulmonary bypass cannot be recommended. (J Thorac Cardiovasc Surg 1996;112:162-7)
\end{abstract}

$T_{\text {oi }}^{\text {he }}$ he influence of cardiopulmonary bypass (CPB) on hemostasis has been the subject of many studies. ${ }^{1-6}$ These studies revealed that abnormalities in platelet function are probably the major cause of postoperative loss of blood in operations with $\mathrm{CPB}^{7,8}$ There are data that suggest that an in vivo lack of platelet agonists (for example, thrombin, which is inhibited by heparin) plays an important role in the observed defect in platelet function. ${ }^{9}$ Although clotting factors decrease during CPB, the

From the Departments of Surgery, ${ }^{\mathrm{a}}$ Anesthesiology, ${ }^{\mathrm{b}}$ Cardiopulmonary Surgery, ${ }^{\mathrm{c}}$ and Hematology, ${ }^{\mathrm{d}}$ Academic Medical Center, University Hospital, Amsterdam, The Netherlands.

Supported in part by a grant from The Regional Red Cross Blood Bank of Amsterdam.

Received for publication Feb. 10, 1995; accepted for publication July 27,1995 .

Address for reprints: M. H. J. van Oers, Department of Hematology, F4-224, Academic Medical Center, University of Amsterdam, Meibergdreef 9, 1105 AZ Amsterdam, The Netherlands.

Copyright (C) 1996 by Mosby-Year Book, Inc.

$0022-5223 / 96 \$ 5.00+0 \quad \mathbf{1 2 / 1 / 6 8 2 3 2}$ levels are still adequate for normal coagulation., Although the only indication for the use of fresh frozen plasma (FFP) is bleeding caused by proven coagulation abnormalities, FFP is often used in patients undergoing cardiac operation, because it is thought to reduce postoperative bleeding complications. ${ }^{1-4,9}$

In view of the risks of transfusion of blood products, for example, the transmission of viral infections, the induction of immunologic transfusion reactions, and the negative influence on the immune system, unnecessary transfusions should be avoided. ${ }^{10-15}$ The aim of the current study was to investigate whether the prophylactic use of FFP in the immediate postoperative phase in patients undergoing cardiac operation decreases blood loss and transfusion requirement.

\section{Patients and methods}

In a prospective, randomized, double-blind study we compared the effects of FFP and of Gelofusine plasma substitute (Vifor Medical SA, Switzerland) on blood loss and transfusion requirement in 50 patients undergoing 
operation with CPB. After the end of the operation the 50 patients (mean age 63 years; 35 men/15 women) were randomly assigned to one of two groups: group I $(n=24)$ received 3 units of FFP and group II $(n=26)$ received 750 $\mathrm{ml}$ of a modified gelatin solution (Gelofusine plasma substitute). All patients underwent coronary artery bypass grafting as the operative procedure. Because we wanted to exclude as many variables as possible no patients undergoing valve replacement were included.

Exclusion criteria were a preexisting coagulopathy (abnormal values in preoperative activated partial thromboplastin time [aPTT], prothrombin time [PT], or platelet count, or platelet dysfunction known from history), a left ventricular ejection fraction of less than $40 \%$, reoperations (because of the usually extended extracorporeal circulation period), and an extracorporeal circulation time that exceeded 2 hours (because prolonged extracorporeal circulation time is known to increase hemostatic defects).

Blinding was ensured by use of two independent investigators, one in the operating room and one in the intensive care unit (ICU) and on the ward. The latter was unaware of whether FFP or Gelofusine plasma substitute had been administered. The randomization envelope was opened at the end of the surgical procedure.

Informed consent was obtained from all 50 patients. The study was approved by the local Institutional Medical Ethical Committee.

Anesthesia and CPB technique. All patients were premedicated according to a standard protocol. Anesthesia was accomplished by means of a standardized high-dose fentanyl regimen in combination with pancuronium bromide for muscle relaxation. Intermittent positive-pressure ventilation was used to maintain normocapnia.

Operation was done according to a standard technique with a midline sternotomy. The extracorporeal circuit contained a Cobe-CML membrane oxygenator (Cobe Laboratories, Lakewood, Colo.). Systemic mild hypothermia $\left(28^{\circ} \mathrm{C}\right)$ was maintained. A pump flow rate of 2.1 $\mathrm{L} / \mathrm{min}$ per square meter was used. The circuit was primed with $500 \mathrm{ml}$ Ringer's lactate solution, $1500 \mathrm{ml}$ polygeline, $100 \mathrm{ml}$ mannitol $20 \%$, and $50 \mathrm{ml} \mathrm{NaHCO}_{3}{ }^{-} 8.4 \%$. An average of $1200 \mathrm{ml}$ of cardioplegic solution (St. Thomas' Hospital No. 1) was used. Systemic anticoagulation was accomplished by intravenous administration of 300 units of heparin per kilogram body weight. After the patient had been weaned from bypass, the heparin was antagonized with protamine sulfate in a ratio of $1.5 \mathrm{mg} / 125 \mathrm{U}$ of the initial heparin dose.

No FFP was given before or during operation. Between the end of operation and the patient's admission into the ICU, either 3 units of FFP or $750 \mathrm{ml}$ of Gelofusine plasma substitute was administered. Homologous packed red blood cells were infused if the hematocrit level was less than $0.20 \mathrm{~L} / \mathrm{L}$ after the bypass procedure or less than 0.25 $\mathrm{L} / \mathrm{L}$ in the ICU. No autotransfusion was done either before or after operation.

Laboratory studies. Blood samples were taken at the following times: before induction of anesthesia, after the administration of heparin, after protamine administration, at the end of the operation, 2 hours after operation in the ICU, 6 hours after operation in the ICU, 24 hours after operation, and on the fifth postoperative day. The blood samples for measurement of hematologic parameters were drawn into $5 \mathrm{ml}$ vacuum containers (Vacutainer, Becton Dickinson Division, Franklin Lakes, N.J.) containing $0.04 \mathrm{ml}$ of potassium ethylene diaminetetraacetic acid. Hemoglobin, hematocrit, platelet, and leukocyte counts were done on an $\mathrm{H} 1$ Technicon instrument (Technicon Instruments Corp., Tarrytown, N.Y.). An additional $5 \mathrm{ml}$ of blood was drawn into $5 \mathrm{ml}$ vacuum containers that contained $0.05 \mathrm{ml}$ of sodium citrate for determination of the following coagulation parameters: aPTT and PT, which were measured with a KC 10 (Amelung, Lengo, Germany), and fibrinogen, which was assayed on an MLA instrument (Medical Laboratory Automation Inc., New York, N.Y.). Intraoperatively, the activated clotting time was measured with the Hemochron instrument (Hemotec, International Technidyne Inc., Edison, N.J.), with use of kaolin-activated tubes. Fluid loss and fluid requirement were recorded until postoperative day 6; additionally, all medications and complications were recorded.

Statistical analysis. Statistical analysis was done by the Mann-Whitney test for unpaired samples, after an analysis of variance. A $p$ value $<0.05$ was considered to be statistically significant.

\section{Results}

Patient groups. The mean age and weight of patients in group I ( $n=24$, male/female ratio 20/4) were 62 years (range 46 to 75 years) and $81 \mathrm{~kg}$ (range 56 to $98 \mathrm{~kg}$ ), respectively. In patients in group II $(n=26$, male/female ratio $15 / 11)$ these values were 63 years (range 49 to 75 years) and $76 \mathrm{~kg}$ (range 54 to $83 \mathrm{~kg}$ ), respectively. The only significant difference $(p<0.01)$ between groups was the male/ female ratio (group I: 5:1, group II: 3:2.2).

Total blood loss in the entire study population ranged from $1625 \mathrm{ml}$ to $1792 \mathrm{ml}$. There was no statistically significant difference between the two groups. On analysis of blood loss during two separate periods (operative period and ICU period), there were also no significant differences between groups (operative period: group I, $896 \pm 212 \mathrm{ml}$; group II, $849 \pm 172 \mathrm{ml}$, and ICU period: group I, $896 \pm 104 \mathrm{ml}$; group II, $776 \pm 76 \mathrm{ml}$; Fig. 1).

As might be expected from the blood loss data, there were no significant differences in the transfusion requirement of packed red blood cells between the groups at any time (operating room: group I, $550 \pm 1077 \mathrm{ml}$; group II, $495 \pm 45 \mathrm{ml}$, ICU: group I, $608 \pm 152 \mathrm{ml}$; group II, $756 \pm 79 \mathrm{ml}$; Fig. 2). No patient in group II received FFP. Additional fluids infused are depicted in Fig. 2. During the entire study period there were no statistically significant differences in fluid balance between the two groups (Fig. 3). 


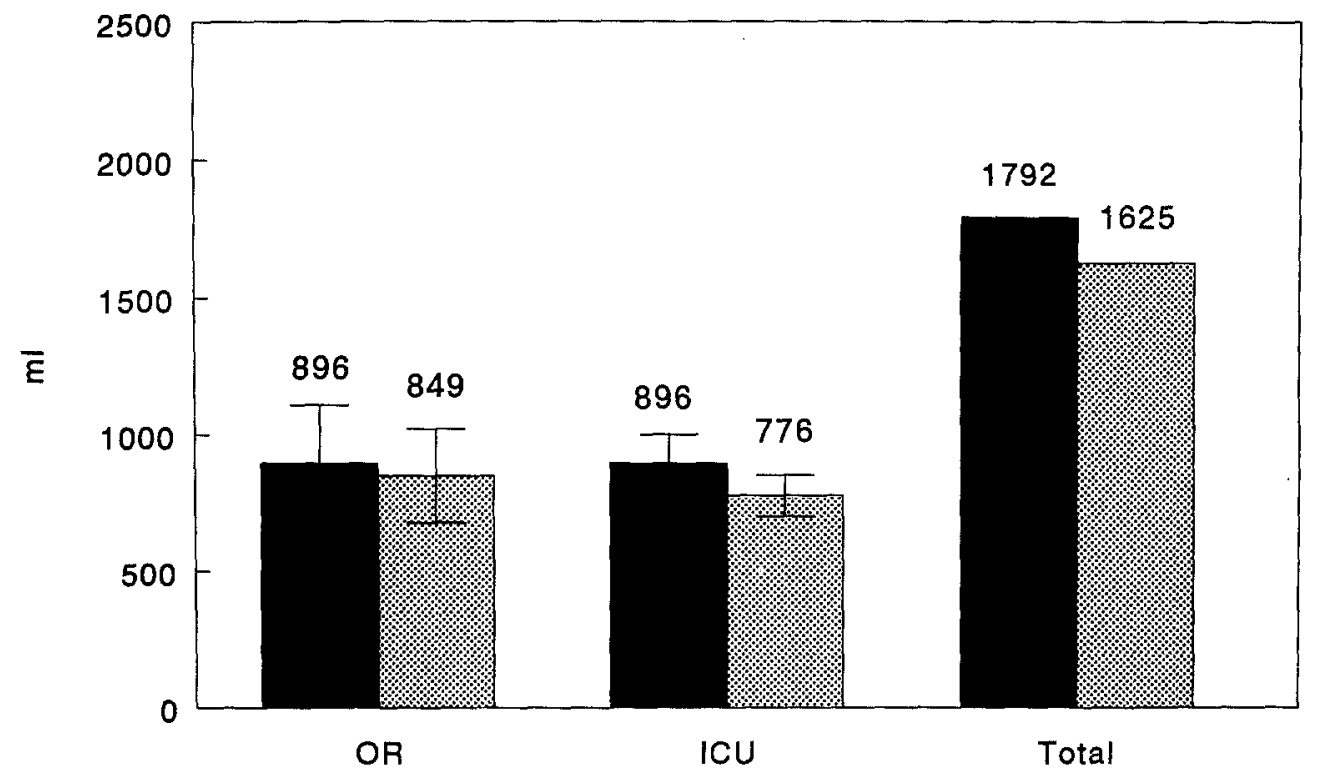

Fig. 1. Blood loss in milliliters in group I (solid bars) and in group II (dotted bars). Values shown for blood loss in operating room $(O R)$, in ICU, and for those two together (Total). Means and standard error of mean are depicted.

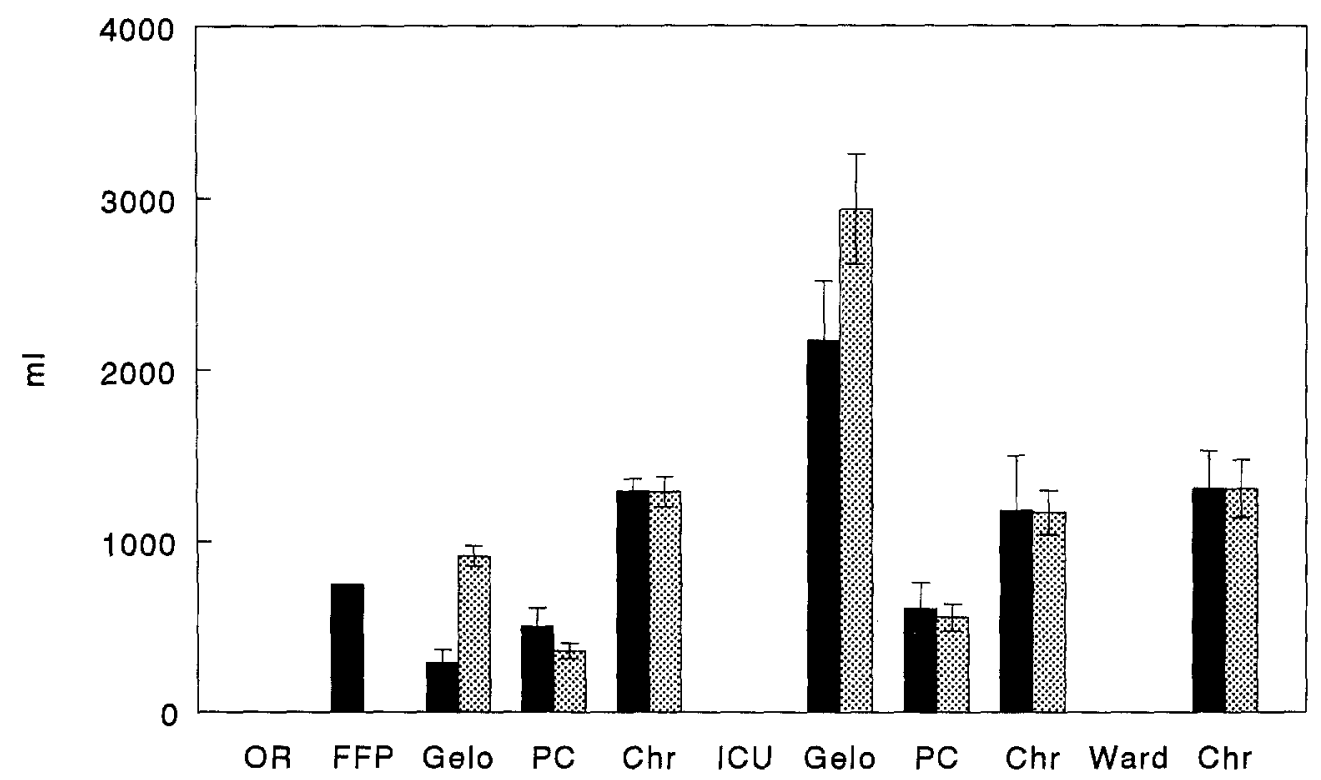

Fig. 2. Infusion regimen (means and standard error of mean in milliliters) during operation $(O R)$, in ICU, and on ward in group I (solid bars) and in group II (dotted bars). Gelo, Gelofusine plasma substitute; $P C$, packed red blood cells; $C h r$, crystalloids.

Hematologic parameters. At all sample times minimal but significant differences between groups were found in hemoglobin and hematocrit levels. Preoperatively these latter parameters were already significantly higher in group I. This was probably a result of the difference in the male/female ratio (group I: 5:1 versus group II: 3:2.2). When statistical correction was done for this confounder, there were no significant differences between groups. The courses of the hemoglobin concentrations in both groups, subdivided into male and female populations, are depicted in Fig. 4.

Hemostasis parameters. Hemostasis parameters are shown in Table I. Besides the expected abnor- 


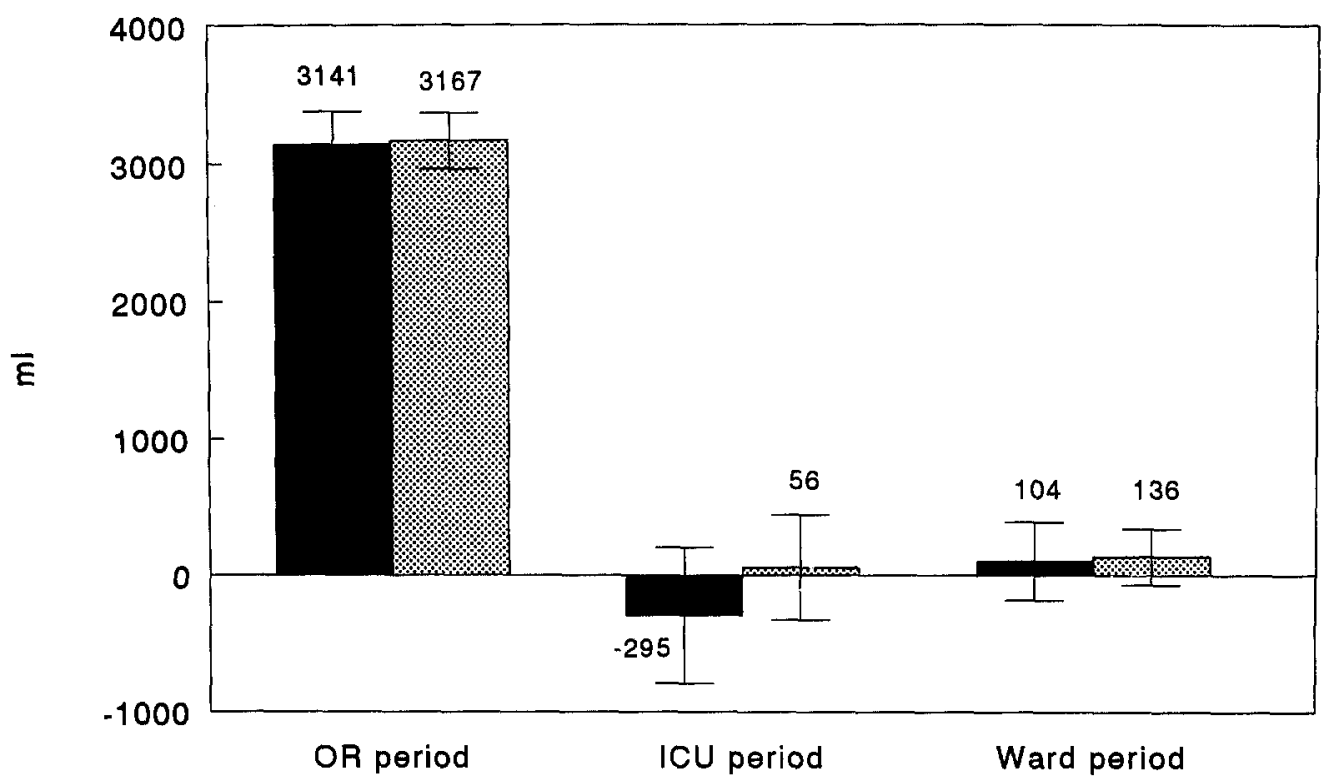

Fig. 3. Cumulative fluid balance (means and standard error of mean in milliliters) in group I (solid bars) and in group II (dotted bars) on arrival in ICU (OR period), on arrival on ward (ICU period), and on leaving hospital (ward period).

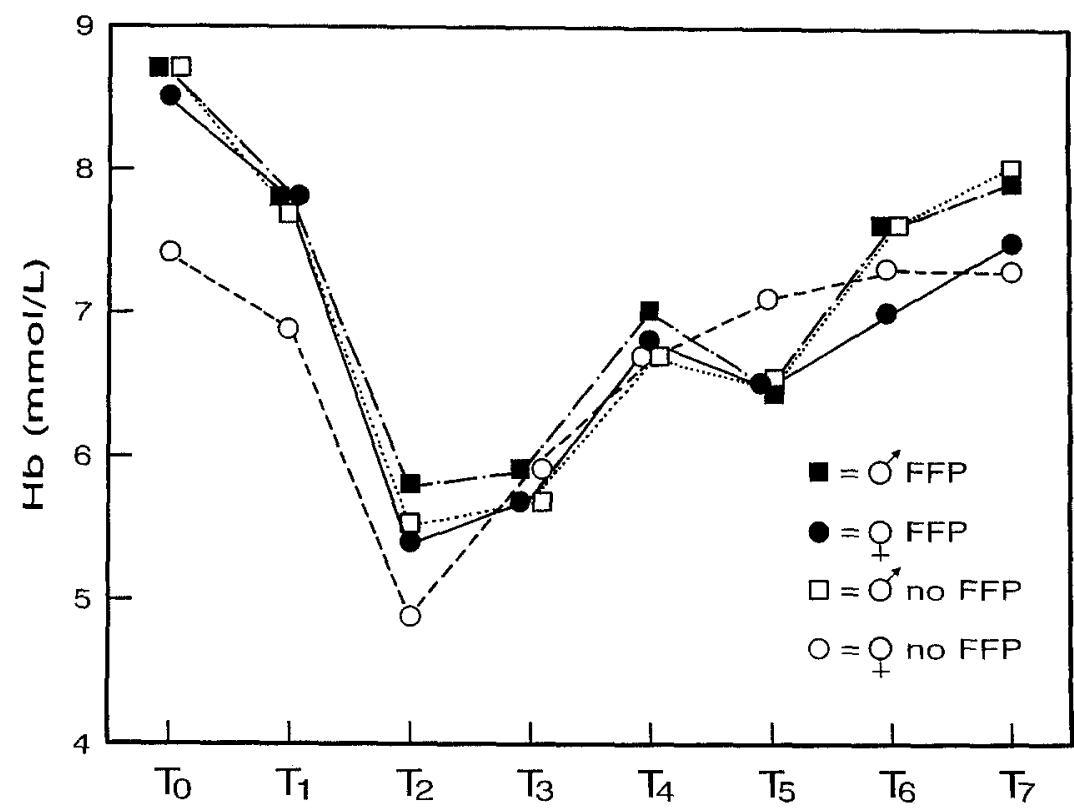

Fig. 4. Hemoglobin $(\mathrm{Hb})$ in means plus or minus standard error of mean in group I men (solid squares) and women (solid circles) and in group II men (open squares) and women (open circles). Samples were taken before operation (TO), after administration of heparin before extracorporeal circulation (T1), after administration of protamine after extracorporeal circulation (T2), at end of operation (T3), 2 hours after operation in ICU (T4), 6 hours after operation in ICU (T5), 24 hours after operation (T6), and on postoperative day $5(T 7)$.

malities caused by heparinization (causing prolongation of the aPTT), the values in both groups remained within the normal range. There were no significant differences between groups. The same was true for the PT. Thrombocyte counts showed the typical course seen during and after operations with CPB. Finally, no significant differences were found between the two groups in the amount of 
Table I. Hemostasis parameters in groups I (FFP) and II (no FFP)

\begin{tabular}{|c|c|c|c|c|c|c|}
\hline \multirow[b]{2}{*}{ Sample } & \multicolumn{2}{|c|}{ aPTT $(\mathrm{sec})$} & \multicolumn{2}{|c|}{$P T(\mathrm{sec})$} & \multicolumn{2}{|c|}{$\begin{array}{c}\text { Thrombocytes } \\
\left(\text { platelets } / \mu l \times 10^{9}\right)\end{array}$} \\
\hline & Group I & Group II & Group I & Group II & Group I & Group II \\
\hline $\mathrm{TO}$ & $24 \pm 3$ & $23 \pm 2$ & $15 \pm 1$ & $13 \pm 1$ & $226 \pm 14$ & $223 \pm 10$ \\
\hline $\mathrm{T} 1$ & $>300$ & $>300$ & $>40$ & $>40$ & $208 \pm 14$ & $207 \pm 12$ \\
\hline $\mathrm{T} 2$ & $36 \pm 4$ & $34 \pm 4$ & $20 \pm 2$ & $17 \pm 1$ & $131 \pm 9$ & $133 \pm 6$ \\
\hline $\mathrm{T} 3$ & $30 \pm 4$ & $34 \pm 44$ & $19 \pm 1$ & $18 \pm 1$ & $135 \pm 10$ & $139 \pm 7$ \\
\hline $\mathrm{T} 4$ & $42 \pm 7$ & $36 \pm 5$ & $16 \pm 1$ & $17 \pm 1$ & $160 \pm 10$ & $161 \pm 8$ \\
\hline T5 & $27 \pm 3$ & $25 \pm 3$ & $17 \pm 1$ & $16 \pm 1$ & $147 \pm 8$ & $152 \pm 7$ \\
\hline T6 & $28 \pm 4$ & $26 \pm 3$ & $20 \pm 1$ & $17 \pm 1$ & $142 \pm 9$ & $141 \pm 7$ \\
\hline $\mathrm{T} 7$ & $32 \pm 3$ & $32 \pm 4$ & $15 \pm 2$ & $17 \pm 2$ & $200 \pm 11$ & $211 \pm 10$ \\
\hline
\end{tabular}

Values given as means plus or minus the standard error of the mean. T0, Before operation; $T 1$, after administration of heparin before extracorporeal circulation; $T 2$, after administration of protamine after extracorporeal circulation; $T 3$, at end of operation; $T 4,2$ hours after operation in ICU; $T 5,6$ hours after operation in ICU; $T 6,24$ hours after operation; $T 7$, fifth postoperative day. There were no significant differences among values.

heparin administered per kilogram of body weight and the subsequent amount of protamine used.

\section{Discussion}

In this study no beneficial effects of the prophylactic administration of FFP could be demonstrated on blood loss, transfusion requirement, or coagulation parameters in patients who underwent operation with CPB. Many investigations have been done with respect to the hemostatic problems often encountered after operations with CPB. In vivo and in vitro studies have shown a number of derangements of the coagulation cascade, platelet counts, and platelet function. ${ }^{1-6}$ Recently, however, there have been indications that thrombocyte function abnormalities are the most important cause of postoperative bleeding complications in patients undergoing CPB. ${ }^{9} \mathrm{CPB}$ may cause qualitative and quantitative thrombocyte abnormalities, which are probably multifactorial. 5, 7, 16,17 Apart from a dilutional effect, adhesion to synthetic surfaces (mainly in the oxygenator), formation of platelet aggregates, and activation and injury of platelets as a result of bloodair interface may play roles. ${ }^{7}$ Additionally, platelet counts may be decreased because of mechanical damage in the roller pump. ${ }^{7,16}$ Hypothermia also contributes to platelet dysfunction after operation. Other causes are platelet aggregation induced by pulmonary artery catheters, heparin, protamine, heparin-protamine complexes, and adenosine diphosphate release from hemolyzed red blood cells. ${ }^{7}$ Because FFP has no proven effect on platelet function there is no reason to transfuse FFP for correction of these abnormalities. ${ }^{6}$ Coagulation abnormalities seem to be transient and clinically less important. The dilution of coagulation factors has been described by various authors. ${ }^{1,2,5,6}$ However, as also observed in our study, coagulation parameters remain well above the levels normally considered to be adequate for hemostasis. ${ }^{1,2,5}$ Furthermore, the amount of FFP generally transfused (1 to 2 units) is inadequate for restoring a severely impaired coagulation system. ${ }^{6}$ As a consequence, routine transfusion of FFP after operations with CPB is not justified.

Finally, CPB has been shown to influence the fibrinolytic system. ${ }^{3}$ The presence of fibrin-split products during and immediately after extracorporal circulation is common. How the fibrinolytic system is activated is not yet completely understood; it is probably triggered through various pathways. ${ }^{3}$ Reports on the successful use of antifibrinolytic agents, such as ( $\epsilon$-aminocaproic acid) and analogues, do suggest that plasminogen may play an essential role. ${ }^{3}$ Furthermore, aprotinin has been reported to reduce blood loss during CPB either by a direct effect on platelets or through a secondary effect, through inhibition of plasmin or the kallikrein system. $^{8,9}$

Nevertheless, many clinicians still administer FFP as a prophylaxis against postoperative bleeding in cardiac operations. As far as we know, up until now only one well-designed clinical study has been done to investigate the effect of FFP on postoperative blood loss and transfusion requirement after operations with $\mathrm{CPB} .{ }^{16}$ In that study by Boldt and colleagues, ${ }^{16}$ the effect in patients undergoing aortocoronary bypass of 2 units of FFP given after the end of extracorporeal circulation $(n=20)$ was compared with findings in a control group $(n=20)$ that did not receive FFP. Various laboratory parameters, including coagulation data, were measured 
before and after extracorporeal circulation up to the first postoperative day. The major results showed that routine administration of FFP has no beneficial effect with respect to hemostatis parameters. ${ }^{16}$ The results of the current study, in which the observation period has been extended to 5 days after operation, are in accordance with those of this previous investigation, thus strengthening the opinion that the administration of FFP after operation with CPB is not justified.

It should be kept in mind, moreover, that transfusion of homologous blood products carries the risk of disease transmission, the most serious of which is the immunodeficiency virus. ${ }^{10-13}$ Classic immunologic transfusion reactions, alloimmunization, and possibly immunosuppression are reasons to be very careful with the administration of blood products. ${ }^{14,18}$ The possible risks of blood component therapy should always be carefully weighed against the beneficial effects.

In conclusion, the current clinical study shows that prophylactic administration of FFP in operations with CPB does not decrease blood loss or the transfusion requirement of packed red blood cells.

We thank Mr. P. T. Goedhart for his skillful assistance. We are grateful to Dr. J. Oosting, statistician, and Mrs. L. Kok-Noorman, scientific editor, Department of Clinical Epidemiology and Biostatistics, for their advice. We would also like to thank the Department of Cardiothoracic Surgery of the Academic Medical Center for their cooperation and the Red Cross Blood Bank of Amsterdam for financial support and cooperation, especially Dr. H. W. Reesink and Dr. R. N. I. Pieterz.

\section{REFERENCES}

1. Van Aken WG, Briët E, Dudok de Wit C, Kunst AJM, van der Meer J. Zijn er nog indicaties voor het transfunderen van plasma. Ned Tijdschr Geneeskd 1991;34:1631-4.

2. Oberman HA. Indications and monitoring of use of fresh frozen plasma as a haemostatic agent. Curr Stud Hematol Blood Transfus 1986;53:125-32.
3. Spiess BD. The contribution of fibrinolysis to post bypass bleeding. J Cardiothorac Vasc Anesth 1991;5:13-7.

4. Barnette RE, Shupak RC, Pontius J, Koneti Rao A. In vitro effect of fresh frozen plasma on activated coagulation time in patients undergoing cardiopulmonary bypass. Anesth Analg 1988;67:57-60.

5. Crosby ET. Perioperative haemotherapy: indications for blood component therapy. Can J Anaesth 1992;39:695-707.

6. Martinowitz U, Goor DA, Ramot B, Mohr R. Is transfusion of fresh frozen plasma after cardiac operations indicated? $\mathrm{J}$ Thorac Cardiovasc Surg 1990;100:92-8.

7. Wildevuur CRH, Eijsman L, Roozendaal KJ, Harder MP, Chang $M$, Van Oeveren W. Platelet preservation during cardiopulmonary bypass with aprotinin. Eur J Cardiothorac Surg 1989;3:533-8.

8. Royston D. Aprotinin prevents bleeding and has effect on platelets and fibrinolysis. J Cardiothorac Vasc Anesth 1991; 5:18-23.

9. Kestin AS, Valeri CR, Khuzi SF, Loskalzo J, Ellis PA, MacGregor $\mathrm{H}$. The platelet function defect of cardiopulmonary bypass. Blood 1993;82:107-17.

10. Leikola J. Transfusion transmitted infectious agents, excluding hepatitis and HIV. Acta Anaesthesiol Scand 1988; 32(suppl 89):20-5.

11. Van der Poel CL, Reesink HW, Schaasberg W, et al. Infectivity of blood seropositive for hepatitis C virus antibodies. Lancet 1990;335:558-60.

12. Iwarson S. Transfusion transmitted non-A, non-B hepatitis. Acta Anaesthesiol Scand 1988;32(suppl 89):13-4.

13. Grillner L. Transfusion transmitted human T-lymphotropic virus infections. Acta Anaesthesiol Scand 1988;32(suppl 89): 16-9.

14. Högman CF. Immunologic transfusion reactions. Acta Anaesthesiol Scand 1988;32(suppl 89):4-12.

15. Gu YJ, Van Oeveren W, Boonstra PW, de Haan J, Wildevuur CRH. Leukocyte activation with increased expression of CR3 receptors during cardiopulmonary bypass. Ann Thorac Surg 1992;53:839-43.

16. Boldt J, Kling D, von Bormann B, Züge M, Hempelman G. Homologes Frischplasma in der Herzchirugie: Mythos oder Notwendigkeit. Anaesthesist 1989:38:353-9.

17. Boldt J, Knothe C, Zickman B, Herold C, Dapper F, Hempelman G. The effects of preoperative aspirin therapy on platelet function in cardiac surgery. Eur J Cardiothorac Surg 1992;6:598-602.

18. Salo M. Immunosuppressive effects of blood transfusion in anaesthesia and surgery. Acta Anaesthesiol Scand 1988; 32(suppl 89):26-34. 